\title{
An assessment plan for lean and green sustainability practices in the supply chain of hotels
}

\author{
R. Al-Aomar \& M. Hussein \\ Abu Dhabi University, UAE
}

\begin{abstract}
This paper aims at developing a practical framework for investigating the application of lean production practices and green technology in the supply chain of the hotel industry in the Abu Dhabi area. The study first develops the construct of a hotel supply chain and identifies the types of waste across the supply chain. Second, the study assesses the extent of knowledge in lean thinking and principles in the industry, explores the adopted lean techniques, and identifies the gap in current existing lean practices. The same approach is applied to analyze the extent of adopting green practices across the supply chain of hotels. Based on the results of gap analysis, the study will develop a framework to assist lean and green deployment in the supply chain of this growing sector of the service economy in Abu Dhabi and across the world. The emphasis will be on reducing the lean-identified seven types of wastes in the hotel supply chain, which typically increases its operational effectiveness and improves service quality. This is also expected to contribute to the increasing effort of incorporating sustainability in the services supply chains. The study results and the developed framework will be shared with the participating Abu Dhabi hotel industry.

Keywords: lean practices, green technology, supply chain sustainability, hotel industry, Abu Dhabi.
\end{abstract}

\section{Introduction}

Sustainability has been of great interest in the last decade for academia and the industrial world because of pressures from various stakeholders to embrace a commitment to sustainability practices [1]. Sustainable organizations are a key 
component of sustainable development in which the environmental and social criteria need to be fulfilled by operations managers, while maintaining competitiveness and meeting customer needs and related economic criteria [2]. This implies that organizations have to satisfy multiple and conflicting objectives such as maximizing profits while reducing operating costs, minimizing the environmental impacts and maximizing the social well-being [3].

A supply chain is often viewed as a network of critical links that connects organizations (stakeholders) together and links each organization's inputs to its outputs. As defined by Bowersox et al. [4], the supply chain refers to all those activities associated with the transformation and flow of goods and services, including money and information flows, from the sources of materials to end users. The term of "reverse logistics" is also used to indicate the flow of material backward from customer to sources through recycling, repair, rework, reuse, refurbishment, and so on. Supply Chain Management (SCM) includes all programs, initiatives, and management activities that aim at effectively running, controlling and improving supply chain operations. Details of supply chain components and functions can be found in [5]. Figure 1 depicts the main components of a service supply chain.

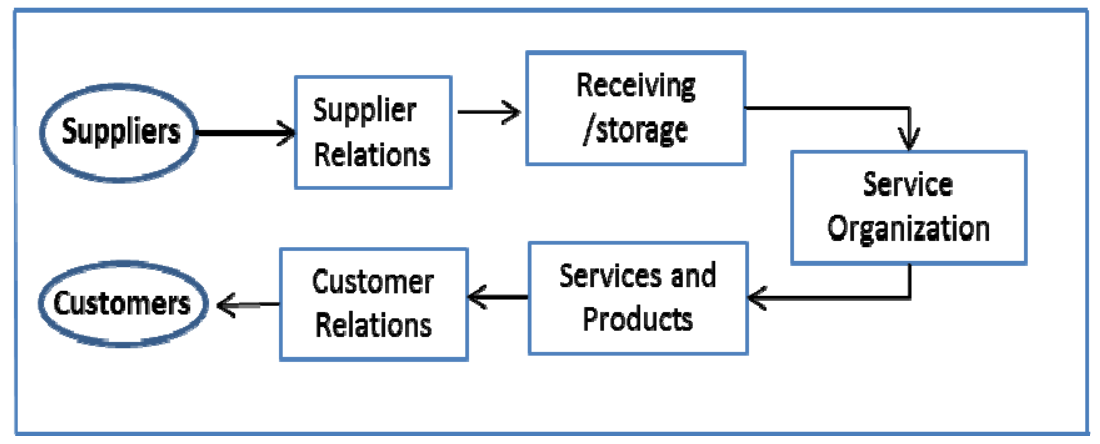

Figure 1: The main components of a service supply chain.

Supply chain sustainability has attracted a growing attention from researchers and practitioners and in various sectors of the economy across the world. That is mainly due to the growing cost of supply chain operations, the increase in stricter environmental regulation and legislations, and the growing competition based on cutting costs and reducing wastes. There is also a clear dearth in existing research on this topic, particularly in service organizations, where the concept and techniques of sustainability are still in the development compared to those in the manufacturing companies. The typical challenge that faces organizations in this regard is how to be productive and profitable while being sustainable.

The integration of sustainability with the supply chain is, therefore, increasingly emphasized in almost all industries through the collaboration of all stakeholders including suppliers and customers. Sustainable supply chain aims to deliver quality products and services across the supply chain while increasing effectiveness, reducing waste and costs, and being environmentally responsible 
[6]. Lean and green practices provide the tools and techniques to achieve such objective.

From a research perspective, reviewed literature showed that adopting lean production practices in services has been an active research area in the last 10 years. Efforts have been focused on proposing lean methods and tools in the various sectors of the economy including health care and hospitality industries. Suárez-Barraza et al. [7] presented a literature analysis and classification of lean service and suggested possible gaps in the research literature from the point of view of researchers and practitioners.

However, few researchers have actually analyzed the application of lean methods to the supply chain of hotel industry or assessed their success in the industry. For example, Vlachos and Bogdanovic [8] presented a survey-based study on the lean thinking in European hotel industry. They focused on assessing lean practices in waste management of selected European hotels. They concluded that value stream mapping techniques have a high impact on detecting and eliminating waste both upstream and downstream the value chain (hotels procurement system and key operations). The same situation applies to the adopting of green practices in the supply chain of hotel industry.

Thus, there is a need for a framework that can be used to assist the deployment of lean and green practices across the supply chain of AD hotel industry.

\section{The assessment framework}

Sustainability in services supply chains is increasingly seen as essential to delivering long-term profitable services while sustaining resources, observing environmental regulations, and positively reflecting on societies. Al-Aomar and Weriakat [9] proposed a framework for a green and lean supply chain applied to construction projects. They concluded that despite the increased amount of attention to developing lean and green supply chains, there is a lack of comprehensive frameworks and a shortage of information on how to integrate environmental initiatives and lean techniques into supply chain functions. This has mainly occurred as a result of four challenges: conceptual, technical, operational, and measurement.

Thus, developing a practical framework for a sustainable supply chain in services in general and in the hotel industry in particular is not an easy task. Several challenges that stem from the nature of the service sector often face the researchers. Some challenge are similar to those in manufacturing companies such as waste identification and reduction and how to maintain efficiency and quality while reducing environmental and social impacts.

When it comes to selecting technologies and techniques that attain and maintain sustainable performance, the level of difficulty increases in the service sectors where lean and green technologies are not yet proven to be effective when applied to the supply chain. Thus, this research will first focus on identifying the construct of the hotel industry supply chain, analyzing pertinent 
waste across the supply chain, then assessing the applicability of lean and green practices. As shown in Figure 2, the key elements of the framework include:

- Supply chain construct

- Waste analysis

- Lean practices (sustainability focus)

- Green practices (sustainability focus)

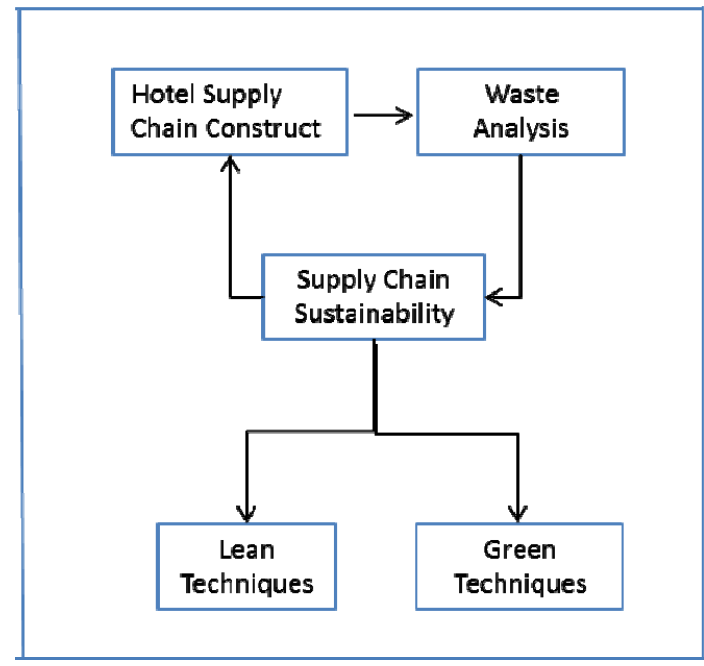

Figure 2: A generic analysis framework for hotel supply chain sustainability.

\subsection{Construct of hotels supply chains}

Before incorporating lean and green practices into the hotel supply chain, it is crucial to understand the construct of the hotel procurement system as well as key hotel operations [10]. As shown in Figure 1, as a service industry, the hotel supply chain is made of the typical elements of Supplier Relationship Management (SRM), logistics, storage, organizational processes and service operations, and of Customer Relationship Management (CRM). These elements which vary from one hotel to another are developed based on the requirements of key hotel services such as:

- $\quad$ Lodging and accommodation

- $\quad$ Restaurants and food services

- Hotel amenities and guest services

- Meetings, events, and conferences

These services require tangible inputs from suppliers and different service providers such as culinary material and other in-bound logistics to ensure efficient delivery of daily hospitability services [11]. Other services in the hotel such as reservation, reception, check-in, check-out, and customer service may not need tangible material as inputs but they also need support and inputs from 
partners and suppliers such as information, technology, payment system, and so on. Almost all hotel services can be oriented around the hotel guest. As an output, hotel provide services such as catering, events management, and accommodation.

\subsection{Waste analysis}

Wastes management is a key business function in most hotels at different star level. This is mainly due to the increased amount of tangible and intangible wastes that are created as a result of hotel services such as accommodation, dining, laundry, and hosted events. This includes food, materials, papers, and so on. The list of wastes in a hotel can also include wastes related to key resources such as water, electricity and energy, and pollution. The list becomes overwhelming when you add to it intangible wastes such as delays, cancellations, complains, errors, excessive inventory, and over capacity. As these wastes directly affect the direct and indirect operational cost, hotels management typically value and support the deployment lean and green techniques that are expected to lead to the reduction or even elimination of different types of wastes. Thus, it is important for any hotel supply chain sustainability framework to analyze the different types of wastes in hotel procurement system and operations and at different stages of the hotel supply chain.

\subsection{Lean practices}

Lean thinking which was started to reduce or eliminate production wastes in Toyota has recently developed into a management philosophy that focuses on increasing the effectiveness of the organization. Womack and Jones [12] describe waste as any activity which uses resources, but creates no value. This includes over production, excess processing, inventory, rework, motion, transport and material handling, defects, failures, setup and underutilizing skills and resources.

The lean supply chain is an approach that is focused on streamlining the flow of goods and information across the supply chain and reducing the supply chain cost by eliminating non-value-added activities through the adoption of lean techniques. To this end, lean principles and tools are applied to the supply chain elements and functions (supplier selection, purchases, shipping, order management, warehousing, manufacturing/processing, transportation, distribution, etc.) to transform it into a value chain. Examples include Kaizen, error-proofing (poke-yoke), flow analysis, line balancing, inventory control, quality-at-the-source, JIT, $5 \mathrm{~S}$, etc.

Several researchers presented applications of lean principles to supply chains. For example, Zarei et al. [13] developed an integrated approach that links Lean Attributes (LAs) and Lean Enablers (LEs) to increase the leanness of a food supply chain. In the hotel industry, the application of lean practices is still limited. Several lean wastes such as overproduction and several lean techniques such as flow analysis are still perceived as irrelevant to hotel operations. A practical framework will, therefore, help in clarifying the expected value of 
adopting lean techniques as well as in facilitating the deployment of lean practices across the supply chain.

\subsection{Green practices}

The main objective of green SCM is to extend the traditional SC to deal with the effects of products and processes. Extended supply chain models often include recycling and remanufacturing operations along with measures to reduce emissions and conserve energy. As an outcome, green SCM can reduce waste, minimize pollution, save energy, conserve natural resources, and reduce carbon emissions. Details on adding the "Green" component to the supply chain management can be found in Azevedo et al. [14].

In the hotel industry, the application of green technology is expanding as a result of strict regulations and the growing customer awareness of environmental concerns. It is therefore important for a hotel sustainability framework to include specific green practices that can be deployed and lead to conservation of resources, reduction of energy and emissions, and efficient recycling. Examples include environmental standards, safety standards, pollution reduction, recycling, reuse, take-back, energy efficiency, water conservation, green technology, green suppliers, clean transport, hazardous material treatment, etc.

\section{Study plan}

The study will adopt a survey-based industry research to collect empirical data from the hotel industry in Abu Dhabi (AD) of the UAE. The study will be first exploratory of the construct and waste types in the hotel supply chain and later it will be confirmatory of factors affecting the sustainability of the hotel supply chain. To this end, a survey will be designed and distributed to about thirty 4 and 5 stars hotels in AD area. The survey will first collect basic hotel information and identify the types of waste currently exist in the hotel supply chain, and check the familiarity of the industry with lean and green techniques. The study will also assess the extent of adopting lean principles and green techniques across the hotel supply chain and find out the technical and cultural challenges and obstacles that limit their application. The results of the survey will be studies and analyzed to answer the key research questions and develop a framework for effective adoption of lean and green practices in the supply chain of AD hotel industry. The framework will be shared with the surveyed hotels and made available to the industry at large in the whole UAE.

The study is conducted as part of a funded research project that will attempt to seek answers to the following key questions pertaining the supply chain of AD hotel industry. Answers to these questions are expected to achieve the defined research objectives:

- What is the construct of the supply chain of AD hotel industry?

- What types of waste currently exist in the supply chain of AD hotel industry?

- $\quad$ To what extent the hotel industry is aware of lean and green practices? 
- What are the lean techniques that are currently adopted in the supply chain of AD hotel industry?

- What are the green techniques that are currently adopted in the supply chain of AD hotel industry?

- What are the technical and cultural challenges for adopting lean and green practices in the supply chain of AD hotel industry?

- What are the benefits of adopting lean and green practices in the supply chain of AD hotel industry?

- What are the key factors that affect the sustainability of a hotel supply chain in $\mathrm{AD}$ ?

- How these factors affect the operational and economic effectiveness of the hotel supply chain in AD?

Towards this end, the research adopts several techniques of exploratory and confirmatory analysis. The study research plan is shown in Figure 3. It is a survey-based study that requires the selected hotels to fill SIPOC charts that identify the hotel supply chain construct, wastes, and lean and green practices. AHP is used to categorize and rank the different types of wastes in the hotel supply chain. The following is a brief description of these techniques.

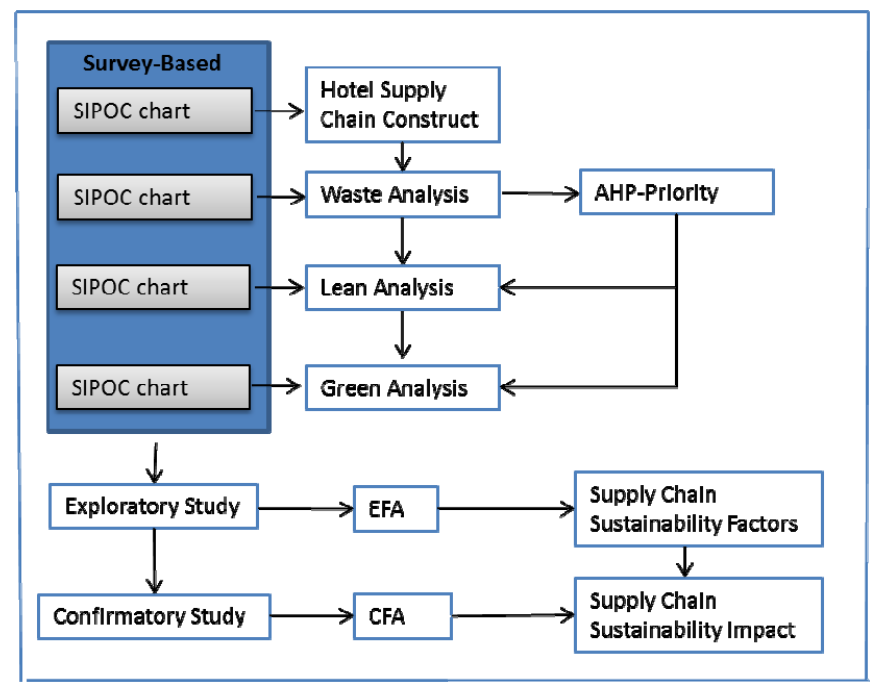

Figure 3: The study research plan.

\subsection{SIPOC analysis}

The Supplier-Input-Process-Output-Customer (SIPOC) chart is used in the survey to provide the hotel supplies and operations manager with a platform to list the relevant information regarding the hotel supply chain construct, wastes, and currently used lean and green practices. Figure 4 shows a template of the used SIPOC chart. 


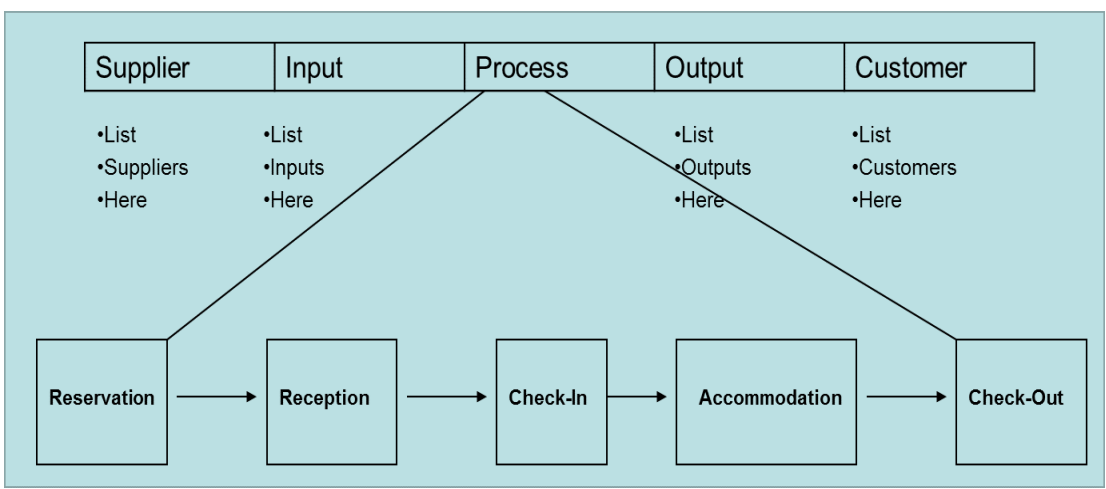

Figure 4: The SIPOC chart template.

\subsection{Analytical Hierarchy Process (AHP)}

Waste analysis will lead to listing different types of wastes currently exist in the supply chain of AD hotel industry. The priority of identified supply chain wastes will be categorized and assessed using AHP which is known for handling both qualitative and quantitative data [15].

AHP is a means of assessment through pair-wise comparisons and relies on the judgment of experts to derive the priority scales. These scales measure the tangibles and intangibles in relative terms. The comparisons are made using a scale of absolute judgment that represents how much more one element dominates another with respect to a given attribute. The approach also provides a measure of inconsistency arising with the judgements. Further details of AHP approach and concerns can be found in Vinodh et al. [16].

\subsection{Exploratory Factor Analysis (EFA)}

EFA is a special form of factor analysis that is used to uncover the underlying structure (latent constructs or model) of a relatively large set of variables. The EFA will be used in this study to identify the latent construct in the sustainability of hotel industry supply chain. The study will measure the correlation (patterns) of selected factors derived from the lean and green practices and categorize them into specific sustainability constructs. The EFA is needed at this stage where we are not sure what factors to include in the supply chain sustainability model. Details of EFA can be found in Thompson [17].

\subsection{Confirmatory Factor Analysis (CFA)}

CFA is a special form of factor analysis that is used to test whether measures of a construct are consistent with a researcher's understanding of the nature of that construct (or factor). In this study and based on the results of the EFA, the study will assess the key factors to include in the hotel supply chain sustainability 
model, we will use CFA to test the model formally and confirm the significance of the selected factors. For example, the model will be used to study the significance of the identified factors on the performance and economics of supply chain sustainability. Details of CFA can be found in Thompson [17].

\section{Expected results}

The expected results from this study include providing comprehensive and conclusive answers to the questions listed in the research plan. In addition, the study is expected to develop a practical framework for adopting lean and green techniques in the supply chain of the AD hotels and in the industry at large. The EFA and CFA are expected to develop a specific model for hotels supply chain sustainability.

\section{References}

[1] Colicchia C., Marchet G., Melacini M. \& Perotti, S., Building environmental sustainability: empirical evidence from Logistics Service Providers. Journal of Cleaner Production. 59, pp. 197-209, 2013.

[2] Cerin, P. \& Karlson, L., Business incentives for sustainability: a property rights approach. Ecological Economics. 40, pp. 13-22, 2002.

[3] Taticchi, P., Tonelli, F \& Pasqualino R., Performance measurement of sustainable supply chains: A literature review. International Journal of Productivity \& Performance Management. 62, pp. 782-804, 2013.

[4] Bowersox, D.J., Closs, D.J, \& Cooper, M.B., Supply chain logistics management. McGraw-Hill, New York, 2002.

[5] Fredendall, L.D. \& Hill, E., Basics of supply chain management. CRC Press, 2000.

[6] Sengupta, K., Heiser, D.R., \& Cook, L.S., Manufacturing and service supply chain performance: a comparative Analysis. Journal of Supply Chain Management, 42 (4), pp. 4-15, 2006.

[7] Suárez-Barraza, M.F., Smith, T., \& Dahlgaard-Park, S.M., Lean Service: A literature analysis and classification. Total Quality Management, 23(4), pp. 359-380, 2012.

[8] Vlachos, I. \& Bogdanovic, A., Lean thinking in the European hotel industry. Tourism Management. 36, pp. 354-363, 2013.

[9] Al-Aomar, R. \& Weriakat, D., A Framework for a Green and Lean Supply Chain: A Construction Project Application. Proceedings of the International Conference on Industrial Engineering \& Operations Management (IEOM), pp. 289-299. Istanbul, Turkey, 2012.

[10] Atkinson, W., Hotel chains awaken to the value of the supply chain. Purchasing, 135 (1), pp. 19-20, 2006.

[11] Fantazy, K.A., Kumar, V., \& Kumar, U., Supply management practices and performance in the Canadian hospitality industry. International Journal of Hospitality Management. 29 (4), pp. 685-693, 2010. 
50 Sustainable Development, Vol. 1

[12] Womack, J.P. \& Jones, D.T., Lean Thinking. New York: Simon and Schuster, 2003.

[13] Zarei, M., Fakhrzad, M.B., \& Jamali Paghaleh, M., Food supply chain leanness using a developed QFD model. Journal of Food Engineering, 102(1), pp. 25-33, 2011.

[14] Azevedo, S.G., Carvalho, H., \& Machado, V.C., The influence of green practices on supply chain performance: A case study approach. Transportation Research Part E: Logistics and Transportation Review, 47(6), pp. 850-871, 2011.

[15] Saaty, T.L., Decision Making for Leaders: the analytical hierarchy process for decision in complex world. RWS publication, Pittsburgh, 2012.

[16] Vinodh, S., Shivraman, \& K.R., Viswesh S., AHP-based lean concept selection in a manufacturing organization. Journal of Manufacturing Technology Management, 23(1), pp. 124-136, 2012.

[17] Thompson, B., Exploratory and confirmatory factor analysis: Understanding concepts and applications. Washington, DC, US: American Psychological Association, 2004. 